\title{
MATERNAL BEHAVIOUR IN THE RABBIT: ENDOCRINE CONTROL OF MATERNAL-NEST BUILDING
}

\author{
M. X. ZARROW, A. FAROOQ*, V. H. DENENBERG, P. B. SAWIN $\dagger$ \\ AND S. ROSS +
}

Department of Biological Sciences and Psychology, Purdue University, Lafayette, Indiana, U.S.A.

(Received 9th May 1963)

\begin{abstract}
Summary. Experiments have been conducted on maternal-nest building and factors affecting its occurrence in the rabbit. Females deprived of nesting material built a nest out of their own body hair and were as successful in rearing young as does which used both body hair and straw; females deprived of body hair (by shaving) and nesting material showed defective maternal behaviour. Interrupting pregnancy by spaying or foetectomy resulted in maternal-nest building. Nest building was induced in spayed females by the withdrawal of progesterone after injections of progesterone and oestradiol for several weeks. Similar regimes did not induce nest building by castrated males. Further experiments strongly suggest that the onset of nest building is governed by the change in the ratio of progesterone to oestrogen.
\end{abstract}

\section{INTRODUCTION}

Hormonal control of certain aspects of maternal behaviour has been reported in a number of widely divergent species such as the rat (Kinder, 1927; Riddle, Lahr \& Bates, 1935), mouse (Leblond, 1940; Koller, 1956), domestic fowl (Riddle, Bates \& Lahr, 1935) and ring dove (Lehrman, 1959; Lehrman \& Brody, 1961); the entire problem of hormonal regulation of parental behaviour in birds and mammals has been reviewed by Lehrman (1961). In the rabbit nest building has been described as one aspect of maternal behaviour and evidence has recently been presented to show that the sex hormones are involved in this behaviour pattern (Zarrow, Sawin, Ross, Denenberg, Crary, Wilson \& Farooq, 1961).

The pregnant rabbit first builds a nest composed of straw, hay, or other suitable material. This has been called the 'straw nest' (Zarrow et al., 1961). Just before or at the time of parturition the mother plucks hair from her own body to line the nest (Sawin \& Curran, 1952; Sawin, Denenberg, Ross, Hafter \& Zarrow, 1960). The straw nest, when lined with this hair, is called a 'maternal nest'. The construction of the maternal nest may begin as soon as the

*This paper is based upon a dissertation presented in partial fulfilment of the requirements for a Ph.D. degree at Purdue University.

†Present address: R. B. Jackson Memorial Laboratory, Bar Harbor, Maine, U.S.A.

$\ddagger$ Present address: Central Office, American Psychological Association, Washington, D.C., U.S.A.

375 
straw nest is completed or after a period of several hours or even a few days.

Maternal-nest building is probably the most striking feature of maternal behaviour in this species. The present investigation is concerned with the importance of the maternal nest in the care of the young, the hormones required, and the mechanism governing the onset of maternal-nest building.

\section{MATERIALS AND METHODS}

Laboratory bred rabbits of the Dutch-belted race were used. The animals were housed under uniform conditions of temperature $\left(20\right.$ to $\left.21^{\circ} \mathrm{C}\right)$ and humidity. Pelleted rabbit diet, timothy hay and tap water was provided ad libitum. The hay was used as food and as material for nest construction.

Pregnancy was diagnosed by palpation 12 or 13 days after mating. The day of mating was designated as Day 1 of pregnancy. Each pregnant rabbit was provided with a wooden nest box measuring $48 \times 27.5 \times 27.5 \mathrm{~cm}$ (inside measurements) with a partition, $7.5 \mathrm{~cm}$ high, dividing the box into two compartments (Zarrow, Sawin, Ross \& Denenberg, 1961).

All surgical operations were performed aseptically under Nembutal anaesthesia, supplemented with ether if necessary. Ovariectomy was usually performed by the bilateral approach, and occasionally by the mid-ventral approach. Each ovary was exposed with the periovarian fat and the Fallopian tube, and was excised after a ligature had been placed around the Fallopian tube and the accompanying blood vessels. The muscle and skin layers were sutured separately with surgical silk.

The male rabbits were castrated by a similar technique. The testis was exteriorized through a small incision in the scrotal sac and the tunica vaginalis, and excised after a ligature had been placed around the spermatic cord and the accompanying blood vessels. The incision was closed by two or three sutures with surgical silk. Post-operative care for all animals consisted of treatment with 300,000 units of procaine penicillin $\mathrm{G}$ intramuscularly and maintenance in a warm room ( 26 to $29^{\circ} \mathrm{C}$ ) overnight.

The steroid hormones, progesterone and oestradiol, were dissolved in peanut oil and injected subcutaneously, at different sites when two or more hormones were administered simultaneously. The human chorionic gonadotrophin (HCG) and prolactin were dissolved in physiological saline solution. HCG was injected intravenously in the marginal ear vein, while prolactin was administered intramuscularly in the hind leg. Pseudopregnancy was induced by the administration of 1000 i.u. HCG on 2 consecutive days. The animals were laparotomized on the 3rd day to ascertain the presence of corpora haemorrhagica; these were taken as evidence of the occurrence of ovulation and the induction of pseudopregnancy. This day was designated as Day 1 of pseudopregnancy.

\section{RESULTS}

NESTING MATERIAL AND MATERNAL GARE

The two components of the maternal nest are nesting material and hair from the mother's body. Some rabbits had their entire hair coat clipped on Day 28 
or 29 of pregnancy while others were not disturbed. In addition, some of the does were given nesting material and others were not, so that there were four treatment groups (Table 1).

Ninety-eight of the 100 control mothers built maternal nests and $87.3 \%$ of the young survived to weaning. All five of the mothers deprived of straw built nests composed of hair alone, delivered their young in the nest and took care of the young normally; $92 \%$ of the young survived through weaning under these conditions. In contrast, clipping the mother's hair had a severe effect upon maternal care. Though five of the seven rabbits built straw nests, only $39.4 \%$ of the young survived in this group. Some of these animals made strenuous efforts to pull out the few tufts of hair left. The removal of both staw and hair resulted in only two of thirty-five, or $5.7 \%$, of the young surviving. Though both hair

TABLE 1

EFFECTS OF NESTING MATERIAL AND TYPE OF NEST BUILT ON MATERNAL CARE IN THE NORMAL PREGNANT RABBIT

\begin{tabular}{|c|c|c|c|c|c|c|}
\hline \multirow{2}{*}{$\begin{array}{l}\text { Treatment or } \\
\text { condition }\end{array}$} & \multirow{2}{*}{$\begin{array}{l}\text { No. } \\
\text { rabbits }\end{array}$} & \multicolumn{2}{|c|}{ No. nests } & \multirow{2}{*}{$\begin{array}{l}\text { Litters } \\
\text { reared }\end{array}$} & \multirow{2}{*}{$\begin{array}{l}\text { Young } \\
\text { survived }\end{array}$} & \multirow{2}{*}{ Remarks about care of young } \\
\hline & & Straw & Maternal & & & \\
\hline $\begin{array}{l}\text { Hair + straw } \\
\text { (control) }\end{array}$ & 100 & 98 & 98 & $94 *$ & $482 / 552 \dagger$ & $\begin{array}{l}\text { Six scattered young, three of } \\
\text { which also cannibalized young. }\end{array}$ \\
\hline Hair alone & 5 & 0 & 5 & 5 & $23 / 25$ & All took care of young. \\
\hline Straw alone & 7 & 5 & 0 & 3 & $13 / 33$ & $\begin{array}{l}\text { Three took care of young, one } \\
\text { litter died and three scattered } \\
\text { and cannibalized young. }\end{array}$ \\
\hline $\begin{array}{l}\text { No hair and no } \\
\text { straw }\end{array}$ & 7 & 0 & 0 & 1 & $2 / 35$ & $\begin{array}{l}\text { Part of one litter survived, two } \\
\text { litters died, and four scattered } \\
\text { and cannibalized young. }\end{array}$ \\
\hline
\end{tabular}

*This includes all litters where one or more of the young were maintained to the weaning period.

TThe numerator is the number of young that survived through weaning. The denominator is the total number of young born.

and straw contribute to the survival of the young, the mother's hair is by far the more important element.

\section{NEST BUILDING AFTER INTERRUPTED PREGNANCY}

During normal pregnancy nest building occurs at the end of gestation. There is good evidence that this behaviour is under the control of endocrine factors (Tietz, 1933). However, observations on the pseudopregnant rabbit show that nest building can take place even though the hormones are allowed to act for a much shorter time (Tietz, 1933). The object of this experiment was to determine whether maternal-nest building would occur when pregnancy was interrupted by ovariectomy or foetectomy. Table 2 summarizes the conditions and findings.

The incidence of maternal-nest building among normal pregnant does was found to be $98 \%$. This is a 'partum' nest-building strain since $86.7 \%$ built their maternal nests on the day of parturition; $8.2 \%$ built nests a day or more before parturition; and $5 \cdot 1 \%$ constructed nests shortly after delivery of the young. 
Pseudopregnancy was induced by the administration of HCG. Seventeen out of twenty does so treated built maternal nests. The nest was always built between the 19th and 21st day after the induction of pseudopregnancy, i.e. at the end of pseudopregnancy.

The foetectomies were performed on Day 19 of pregnancy. The foetuses were removed with the amnion but the placentae were left in situ. All five does built nests within 3 to 4 days of the operation. The placentae were aborted before nest building or were found to be in the process of resorption. This observation differs from those reported by earlier investigators (Hammond, 1917; Mall, 1921). According to these authors the placentae are expelled at the normal term of pregnancy and this is followed by nest building. However, van Wagenen \& Newton (1943), who were able to obtain functional survival of the monkey's placenta after removing the foetus, also reported that the rabbit is an unfavourable animal for the study of placental retention after the experimental destruction of foetuses since the isolated placenta soon became detached and was expelled or later found in the uterine cavity.

TABLE 2

MATERNAL-NEST BUILDING IN THE RABBIT

\begin{tabular}{l|c|c|c}
\hline & & \multicolumn{2}{|c}{ Maternal nest } \\
\cline { 2 - 3 } Treatment or condition & No. rabbits & No. built & $\begin{array}{c}\text { Percentage } \\
\text { built }\end{array}$ \\
\hline $\begin{array}{l}\text { Normal pregnancy } \\
\text { Pseudopregnancy }\end{array}$ & 100 & 98 & 98 \\
Foetectomy on Day 19 & 20 & 17 & 85 \\
of pregnancy & 5 & 5 & 100 \\
21 of pregnancy & 5 & 5 & 100 \\
\hline
\end{tabular}

The five pregnant animals ovariectomized on Day 21 of gestation exhibited maternal-nest building after abortion of the foetuses. The sequence of events in the spayed doe included the abortion of foetuses within 2 to 3 days of the operation followed by nest building within $12 \mathrm{hr}$.

\section{NEST BUILDING AFTER HORMONE TREATMENT}

Various combinations of oestrogen, progesterone and prolactin were administered to male and female rabbits after gonadectomy in attempts to induce nest building. Hormone treatment was started after an interval of 2 to 3 weeks. Forty-eight spayed does were subjected to nine experimental regimes in an attempt to induce nest building (Table 3). Treatment $\mathrm{A}$ involved the daily injection of $5 \mu \mathrm{g}$ of oestradiol for a period of 56 days. The animals also received $1 \mathrm{mg}$ of progesterone during the 2nd and 3rd week followed by $2 \mathrm{mg}$ of progesterone for the remaining period. Twenty i.u. prolactin was injected daily for the last 2 weeks. Within 3 or 4 days of the cessation of hormone treatment, all ten rabbits built maternal nests. An attempt to reduce the period of treatment to 3 weeks failed to induce nest building in two rabbits. 
Since maternal-nest building occurs in the rabbit during pregnancy, a period of exposure to the proper hormones for a period of approximately 30 days should be sufficient to induce it. Furthermore, since maternal-nest building, during either pregnancy or pseudopregnancy, is associated with a decline in the circulating level of progesterone, this hormone was withdrawn 3 days before the cessation of oestrogen injections. Under this type of regime (Treatment $\mathrm{G}$ ), all five rabbits built maternal nests. It is of interest to note that prolactin was not necessary in this experiment; furthermore, if both the oestrogen and progesterone treatment were stopped simultaneously (Treatment D), nest building failed to occur. In an attempt to reduce further the length of treatment, ten rabbits were injected with $5 \mathrm{\mu g}$ oestradiol on Days 1 to 18 and $4 \mathrm{mg}$ progesterone on Days 2 to 15 (Treatment E) and all ten animals built nests. Once again, if treatment with oestradiol and progesterone was maintained until Day 18 (Treatment F) and simultaneously stopped, nest building failed to occur. In Treatment $G$ the treatment time was reduced to 15 days for oestradiol and to 11 days for progesterone; this failed to induce nesting activity in any of three does. In two control experiments rabbits received only progesterone (Treatment H) or oestradiol (Treatment I). Neither treatment induced any nest-building activity.

Castrated males were subjected to Treatments $\mathrm{A}$ and $\mathrm{E}$, both of which had resulted in maternal-nest building in all the spayed females. Six males underwent Treatment A; three underwent Treatment E; and three received double the doses of the $\mathrm{F}$ regime (i.e. $10 \mu \mathrm{g}$ oestradiol and $8 \mathrm{mg}$ progesterone). None showed any signs of nest-building activity.

\section{ONSET OF NEST BUILDING}

Maternal-nest building has been found to occur at the time of parturition, near the end of pseudopregnancy, and after ovariectomy in the pregnant animal. The onset of nest construction is always associated with a fall in progesterone levels. Added support for this hypothesis was obtained from Treatments $\mathrm{E}$ and $\mathrm{F}$ in the prior experiment in which the progesterone treatment was terminated before the cessation of the oestrogen treatment.

The purpose of this experiment was to determine whether maternal-nest building in the pregnant rabbit could be blocked, or its onset delayed or brought forward, by appropriate hormone manipulation. Starting on Day 28 of pregnancy, twelve does received daily treatments of $4 \mathrm{mg}$ progesterone $(2 \mathrm{mg}$ twice daily) until Day 35 of gestation. Nest building was inhibited in all but one of these rabbits. Parturition was delayed in all animals and appeared only 3 to 4 days after the withdrawal of progesterone injections. The dead foetuses were expelled over a period of several days. In a second group of ten pregnant rabbits treated in a similar fashion with a dose of $2 \mathrm{mg}$ progesterone, the delay as well as the subsequent onset of parturition was comparable to the former group, but $90 \%$ of the animals did build a maternal nest. The onset of nest building varied from normal to a slight delay of 1 or 2 days.

It is evident from the above results that the onset of maternal-nest behaviour may depend on a critical ratio between progesterone and oestradiol. Therefore, 
either a decrease in progesterone or an increase in oestrogen should result in maternal-nest building. One way to test this hypothesis was to attempt to reverse the existing progesterone dominance during the course of pregnancy by giving oestrogen.

Ten pregnant rabbits were given $10 \mu \mathrm{g}$ of oestradiol benzoate daily on Days 20,21 and 22 of pregnancy. Nine of these animals built a maternal nest between Days 22 and 24 of gestation. Pregnancy continued normally in five of the rabbits which had built premature nests; all five built a second maternal nest at the time of parturition. In the remaining four does the treatment caused resorption of foetuses and no further nest was built at the end of pregnancy.

TABLE 3

\begin{tabular}{|c|c|c|c|c|c|c|c|c|}
\hline \multirow{3}{*}{ Schedule } & \multicolumn{6}{|c|}{ Treatment } & \multicolumn{2}{|c|}{ No. rabbits } \\
\hline & \multicolumn{2}{|c|}{ Oestradiol } & \multicolumn{2}{|c|}{ Progesterone } & \multicolumn{2}{|c|}{ Prolactin } & \multirow{2}{*}{ Treated } & \multirow{2}{*}{$\begin{array}{l}\text { Built } \\
\text { nests }\end{array}$} \\
\hline & $\mu g$ & Days & $m g$ & Days & i.u. & Days & & \\
\hline A & 5 & 1 to 56 & $\begin{array}{l}1 \\
2\end{array}$ & $\begin{array}{r}8 \text { to } 21 \\
22 \text { to } 56\end{array}$ & 20 & 42 to 56 & 10 & 10 \\
\hline B & 5 & 1 to 21 & $\begin{array}{l}2 \\
4\end{array}$ & $\begin{array}{r}8 \text { to } 14 \\
15 \text { to } 21\end{array}$ & 20 & 15 to 21 & 2 & 0 \\
\hline C & 5 & 1 to 31 & $\begin{array}{l}2 \\
4\end{array}$ & $\begin{array}{r}9 \text { to } 18 \\
19 \text { to } 28\end{array}$ & & & 5 & 5 \\
\hline $\mathrm{D}$ & 5 & 1 to 28 & $\begin{array}{l}2 \\
4\end{array}$ & $\begin{array}{r}9 \text { to } 18 \\
19 \text { to } 28\end{array}$ & & & 3 & 0 \\
\hline $\begin{array}{l}\mathbf{E} \\
\mathbf{F} \\
\mathbf{G} \\
\mathbf{H} \\
\mathbf{I}\end{array}$ & $\begin{array}{l}5 \\
5 \\
5 \\
5\end{array}$ & $\begin{array}{l}1 \text { to } 18 \\
1 \text { to } 18 \\
1 \text { to } 15 \\
1 \text { to } 18\end{array}$ & $\begin{array}{l}4 \\
4 \\
4 \\
4\end{array}$ & $\begin{array}{l}2 \text { to } 15 \\
2 \text { to } 18 \\
2 \text { to } 11 \\
1 \text { to } 15\end{array}$ & & & $\begin{array}{r}10 \\
3 \\
3 \\
5 \\
7\end{array}$ & $\begin{array}{r}10 \\
0 \\
0 \\
0 \\
0\end{array}$ \\
\hline
\end{tabular}

\section{DISGUSSION}

The pattern of maternal-nest building and hair loosening has already been described (Sawin \& Curran, 1952; Sawin et al., 1960). The observation that a significant association exists between scattering and cannibalism on the one hand and poorly constructed and poorly lined nests on the other was first made by Sawin \& Grary (1953). The results presented in Table 1 clearly demonstrate how the inadequacy or absence of the maternal nest can adversely affect the total maternal performance of the rabbits. Fewer young died among those provided with straw alone than among those with neither straw nor hair. This reflects the role of the nesting material in insulation and conservation of heat. Although this point was not investigated in the present study, it is known that the newborn young of a number of mammalian species show poor temperature 
regulation. However, heat loss does not account for the abnormal behaviour of the mother without nests, in particular the extremely high incidence of scattering and cannibalism. Seven of the fourteen animals in these two groups exhibited this abnormal behaviour as compared to $6 \%$ in the control population.

Rabbits which could use only their body hair to build a nest were as successful in rearing their young in a warm temperature as those animals which used both hair and straw (Table 1). The use of straw or other suitable material seems to be a part of the behavioural repertoire of the animal in the natural habitat and may be essential for rearing the young in a cold environment.

The administration of hormones (Table 3 ) for 31 or 18 days (comparable to normal pregnancy and pseudopregnancy) was enough to bring about nest building. The failure to induce nest building in experiments where the two ovarian steroids were discontinued simultaneously was, therefore, not due to a lack of hormones but rather due to a lack of appropriate conditions (an optimum ratio of progesterone-oestrogen) for the onset of maternal-nest building.

The onset of maternal-nest building at or about the end of pregnancy or pseudopregnancy is obviously associated with a fall in the circulating level of progesterone. The same applies to nest building after the termination of gestation by spaying or after abortion, since this is followed by involution of the corpora lutea. This is in agreement with previous observations (Kinder, 1927; Tietz, 1933; Klein, 1956). It is further supported by the findings of Schofield (1957) that the progestogen-oestrogen ratio is reversed in the rabbit before parturition. Again, the escape of the myometrium from progesterone dominance in the last 2 or 3 days of pregnancy points to relative progesterone deficiency (Csapo, 1956).

There is further evidence that the progesterone-oestrogen ratio is critical in the finding that progesterone injections inhibited nest building, while the administration of exogenous oestrogen on Days 20 to 22 of pregnancy, at a time when the progesterone level is higher than the oestrogen level, resulted in the occurrence of nest building.

The experimental treatments failed to induce nest building when the two steroids were stopped simultaneously, whereas nest building was always obtained when progesterone was discontinued 2 or 3 days before the cessation of oestradiol injections. This procedure perhaps results in the decline of progesterone level until an optimum ratio of the two steroids is reached, and induces the onset of maternal-nest building. Mikhail, Noall \& Allen (1961) report that the sudden withdrawal of progesterone, after treating spayed non-pregnant rabbits for 25 days with oestrogen and progesterone, results promptly in nest building.

Significant differences exist with regard to the onset or time of nest building in different races of rabbits (Sawin \& Crary, 1953). It is tempting to speculate that the reversal from progesterone dominance to oestrogen dominance may be occurring at different times in different races of rabbits and that the onset of maternal-nest building is correlated with this shift in hormonal balance.

Treatments that induced maternal-nest building in the spayed rabbit were unsuccessful in the castrated male rabbit. It is possible that the failure to induce nest building in castrated males may be due to unsuitable dosage, timing, or 
length of treatment. On the other hand, it may very well be due to a sex difference controlled by the male genotype.

In the present experiments the complete nest building pattern was reproduced by treatment with progesterone and oestradiol. The findings are in accord with Lehrman's (1961) conclusion that nest building in the rabbit is associated with the cessation of progesterone secretion. However, although nest building can be elicited in the absence of exogenous prolactin, the release of endogenous prolactin cannot be ruled out, and the role of prolactin in maternalnest building in the rabbit is still to be discovered.

\section{ACKNOWLEDGMENTS}

This work was supported by research grant GM 06263-04 from the Division of General Medical Sciences, National Institutes of Health, U.S. Public Health Service.

Progesterone and oestradiol were obtained through the courtesy of $\mathrm{Dr}$ Preston Perlman Schering Corporation. Human chorionic gonadotrophin was obtained through the courtesy of Dr J. B. Jewell, Ayerst Laboratories. Prolactin was obtained through the courtesy of Dr Aleck Borman, Squibb Institute.

\section{REFERENCES}

Csapo, A. (1956) The mechanics of the effect of the ovarian steroids. Recent Progr. Hormone Res. 12, 405. HAMmOND, J. (1917) On the causes responsible for the developmental progress of the mammary glands in the rabbit. Proc. roy. Soc. B, 89, 534.

KINDER, E. F. (1927) A study of the nest building activity of the albino rat. F. exp. Zool. 47, 117.

KLEIN, M. (1956) Aspects biologiques de l'instinct reproducteur dans le comportement des mammifères. L'Instinct dans le Comportement des Animaux et de l'Homme. Ed. P. P. Grasse. Masson, Paris.

Koller, G. (1956) Hormonale und psychische Steuerung beim Nestbau weisser Mause. Verh. dtsch. zool. Ges. $19,123$.

Leblond, C. P. (1940) Nervous and hormonal factors in the maternal behaviour of the mouse. F. genet. Psychol. 57, 327.

Lempman, D. S. (1959) On the origin of the reproductive behavior cycle in doves. Trans. N.Y. Acad. Sci. 21, 682.

LeHRMAN, D. S. (1961) Hormonal regulation of parental behavior in birds and infrahuman mammals. Sex and Internal Secretions. 3rd Edn, vol. 2. Ed. William C. Young. Williams \& Wilkins, Baltimore.

LEHRMAN, D. S. \& BRODY, P. N. (1957) Oviduct response to estrogen and progesterone in the ring dove (Streptopelia risoria). Proc. Soc. exp. Biol., N.Y. 95, 373.

MaLL, F. P. (1921) Studies on abortuses: a survey of pathologic ova in the Carnegie embryological collection. Contr. Embryol. Carneg. Instn. 12, 3.

Mikhall, G., Noall, M. W. \& Allen, W. M. (1961) Progesterone levels in the rabbit ovarian vein blood throughout pregnancy. Endocrinology, 69, 504.

Riddle, O., Bates, R. W. \& Lahr, E. L. (1935) Prolactin induces broodiness in fowl. Amer. F. Physiol. 111,352 .

Riddle, O., LAHR, E. L. \& BAtes, R. W. (1935) Effectiveness and specificity of prolactin in the induction of the maternal instinct in virgin rats. Amer. F. Physiol. 113, 109.

Sawin, P. B. \& Crary, D. D. (1953) Genetic and physiological background of reproduction in the rabbit. II. Some racial differences in the pattern of maternal behaviour. Behaviour, 6, 128.

Sawin, P. B. \& Curran, R. H. (1952) Genetic and physiological background of reproduction in the rabbit. I. The problem and its biological significance. F. exp. Zool. 120, 165.

Sawin, P. B., Denenberg, V. H., Ross, S., Hafter, E. \& Zarrow, M. X. (1960) Maternal behavior in the rabbit: hair loosening during gestation. Amer. F. Physiol. 198, 1099.

ScHofield, B. M. (1957) The hormonal control of myometrial function during pregnancy. F. Physiol. $138,1$.

TIETz, E. G. (1933) The humoral excitation of the nesting instincts in rabbits. Science, 78, 316. 
Wagenen, G. van \& Newton, W. H. (1943) Pregnancy in the monkey after removal of the fetus. Surg. Gynec. Obstet. 77, 539.

Zarrow, M. X., SAwin, P. B., Ross, S. \& Denenberg, V. H. (1961) Maternal behavior in the rabbit and a consideration of its endocrine basis. The Roots of Behavior. Ed. E. L. Bliss. Hoeber, New York.

Zarrow, M. X., Sawin, P. B., Ross, S., Denenberg, V. H., Crary, D., Wilson, E. D. \& Farooe, A. (1961) Maternal behaviour in the rabbit: evidence for an endocrine basis of maternal-nest building and additional data on maternal-nest building in the Dutch-belted race. F. Reprod. Fertil. 2, 152. 